\title{
LAS ACTITUDES DE LOS ESPAÑOLES ANTE LAS MEDIDAS DE JUSTICIA TRANSICIONAL RELATIVAS A LA GUERRA CIVIL Y AL FRANQUISMO
}

\section{SPANIARD'S ATTITUDES TOWARDS CIVIL WAR AND FRANCOISM'S TRANSITIONAL JUSTICE MEASURES}

\author{
Paloma Agullar \\ UNED. España \\ paguilar@poli.uned.es \\ LAIA BALCELLS \\ Institut d'Anàlisi Econòmica, CSIC. España \\ laia.balcells@iae.csic.es \\ HÉctor Cebolla \\ UNED. España \\ hcebolla@poli.uned.es
}

\section{RESUMEN}

Se ha hablado mucho de los determinantes institucionales de la justicia transicional (JT). Sin embargo, el conocimiento de qué variables condicionan las actitudes de los ciudadanos ante las políticas de reparación por violaciones de los derechos humanos sigue siendo escaso. En este artículo se explota una encuesta original del CIS realizada en 2008 a una muestra representativa de la población española. Un año antes, el Gobierno socialista había aprobado la conocida como "ley de Memoria Histórica", dirigida a la reparación de las víctimas de la guerra civil, la dictadura franquista y la transición a la democracia. En este trabajo analizamos las actitudes individuales ante un conjunto de políticas de JT, como las comisiones de la verdad, los juicios a los violadores de derechos humanos y las medidas de reparación simbólica. Estudiamos el efecto de diferentes conjuntos de variables explicativas: factores individuales (sociodemográficos e ideológicos), factores familiares y de socialización y, finalmente, factores contextuales. Los resultados revelan que tanto la ideología como la victimización de la familia del entrevistado por parte de la dictadura son muy relevantes para explicar las actitudes individuales ante las políticas de JT. Los factores contextuales (regionales) resultan, asimismo, cruciales.

\section{Palabras Clave}

Democratización, Justicia transicional, Memoria histórica, Socialización, Trauma, Victimización, Violencia política. 


\begin{abstract}
Much has been said about the institutional determinants of transitional justice (TJ). Yet, we still have little knowledge about the determinants of citizens' attitudes towards restorative policies aimed at addressing human rights violations of the past. This paper draws from an original survey implemented on a representative sample of Spanish citizens in 2008. One year before, the Spanish socialist government approved the so-called "Law of Historical Memory" that aimed at the restitution of the victims of the Spanish Civil War, the Francoist dictatorship and the transition to democracy. We analyze individual-level attitudes towards a set of TJ policies, i.e. truth commissions, trials, and symbolic reparations. We study the effect of different sets of variables: individual factors (sociodemographic and ideological), family and socialization factors, and context-related factors. Our results reveal that both ideology and family victimization during the dictatorship are highly relevant for explaining individual attitudes towards TJ policies. Contextual (regional) factor show to be crucial as well.
\end{abstract}

\title{
KEYWORDS
}

Democratization, Historical Memory, Political Violence, Socialization, Transitional Justice, Trauma, Victimization.

\section{INTRODUCCIÓN ${ }^{1}$}

La expresión "justicia transicional" (en lo sucesivo, JT) alude a un conjunto de medidas adoptadas durante los procesos de democratización -y, en algunos casos, una vez que la democracia se ha consolidado (Aguilar 2008a; 2008b)-, para tratar de reparar a las víctimas de la violencia perpetrada en una dictadura o en el contexto de un conflicto armado. También se persigue con ellas "promover la justicia, la paz y la reconciliación" (De Greiff y Duthie 2009:4) en sociedades divididas por las mencionadas experiencias traumáticas con el fin de que una convivencia democrática de calidad, en la que se respeten los derechos humanos, sea posible.

En términos generales, las políticas de JT suelen adaptar alguna (o varias) de las siguientes formas: (1) medidas judiciales dirigidas a castigar a los perpetradores de violaciones de derechos humanos y/o a privarlos de privilegios adquiridos de forma ilegítima; (2) políticas orientadas a la reparación material y/o simbólica de las víctimas; y (3) procedimientos de revelación de la verdad. La primera categoría puede incluir procesos judiciales e incluso la anulación de amnistías autoproclamadas por los gobiernos salientes; con ello se pretende permitir la acción de la justicia. También puede conllevar la aprobación de normas destinadas a expropiar a los antiguos gobernantes autoritarios de aquellos bienes adquiridos de un modo ilegítimo, así como a eliminar de los cargos

\footnotetext{
${ }^{1}$ Agradecemos los comentarios de Juan Linz, Roger Petersen, Gemma Sala, Elisabeth Wood, así como de los participantes en el panel de Justicia Transicional de la Midwest Political Science Association (2009) y en la 4. ${ }^{\text {a }}$ Conferencia sobre Conflictos Civiles de MIT-Harvard-Yale (2009). También queremos agradecer al Centro de Investigaciones Sociológicas (CIS) la realización de la encuesta en la que está basada esta investigación; su revisión final se benefició del intercambio de opiniones que mantuvimos con varias personas del Departamento de Investigación. Eudald Lerga, Ana Arjona, David Backer y Pablo De Greiff nos hicieron llegar valiosos comentarios. José Ventura tradujo la primera versión de este artículo. Por último, agradecemos las críticas y sugerencias de los dos evaluadores anónimos que han revisado nuestro texto.
} 
públicos (o a impedir el acceso a los mismos) de personas con un pasado estrechamente vinculado al régimen anterior (por ejemplo, purgas o depuraciones). Las reparaciones pueden consistir en diversas políticas de compensación material (por ejemplo, en la restitución de derechos de propiedad confiscados por el régimen anterior 0 en la provisión de pensiones 0 indemnizaciones a las víctimas 0 a sus familiares), o simbólica (por ejemplo, memoriales dedicados a las víctimas, leyes que proclamen la ilegalidad del régimen anterior o petición oficial de disculpas a las víctimas y a sus familiares). Finalmente, los procedimientos de revelación de la verdad suelen comprender la creación de comisiones de la verdad y la desclasificación de documentos.

Aunque el estudio de la JT constituye un campo floreciente en la investigación social y política, siguen existiendo algunas lagunas importantes en el mismo. Por ejemplo, la inmensa mayoría de la literatura sobre JT se ha centrado en explicar los determinantes institucionales de estas políticas, ${ }^{2}$ y existe un conocimiento escaso tanto de sus consecuencias (Merwe et al. 2009; Payne et al. 2008) como de la visión que sobre la JT tiene la opinión pública (Thoms et al. 2008). Nuestro trabajo trata de contribuir a la literatura especializada precisamente en esta última dirección.

En algunos trabajos (Skaar 1999), la opinión de la ciudadanía sobre las medidas de JT se ha inferido de las presiones ejercidas por las organizaciones sociales. Pero este es un presupuesto problemático, ya que no puede suponerse que exista una relación directa entre las demandas impulsadas por organizaciones o grupos de interés y las preferencias generales de la ciudadanía -pese a que pueda existir cierta conexión entre ellas. Aunque esta advertencia puede aplicarse de un modo general a cualquier política pública (véase Becker 1983), es especialmente relevante en el caso de la JT por varias razones: en primer lugar, es probable que la sociedad civil se encuentre debilitada tras una experiencia autoritaria y/o un conflicto violento y que los recursos organizativos para presionar a favor de la JT sean bastante escasos. En segundo lugar, aunque en la sociedad exista el deseo subyacente de medidas de este tipo, bien puede ocurrir que la población no las reclame abiertamente por miedo a la desestabilización política, el poder residual de los actores represivos u otras preocupaciones similares. Finalmente, podría ocurrir que las presiones ejercidas por varios actores sociales a favor de la TJ fuesen representativas únicamente de algunos grupos con preferencias muy intensas (por ejemplo, las víctimas y sus familiares), y no necesariamente de la sociedad en general.

Otras contribuciones académicas sobre las demandas sociales de JT se basan en investigaciones etnográficas que incluyen entrevistas y/u observación participante (Theidon 2006), en entrevistas a subgrupos específicos de la población como las víctimas (Grodsky 2008; Strover y Weinstein 2004; International Center for Transitional Justice 2004; 2008; Espinoza Cuevas et al. 2003), o en el análisis de los grupos de presión

${ }^{2}$ Kritz 1995; McAdams 1997; Teitel 2000; Barahona de Brito, González y Aguilar 2001; Elster 1998; 2004; 2006; Nalepa 2008; 2010. 
(Backer 2003). En resumen, con muy pocas excepciones, los académicos no se han basado en datos sistemáticos y generalizables sobre las actitudes del conjunto de la población de un país hacia las políticas de JT. ${ }^{3}$

En este artículo, realizamos una doble contribución empírica a esta literatura: en primer lugar, analizamos datos de una encuesta, hasta ahora sin explotar, que es representativa de la población española. Dicha encuesta fue diseñada por los autores de este artículo con la colaboración del Centro de Investigaciones Sociológicas, institución que también se encargó de realizar el trabajo de campo en abril de 2008 (estudio n. ${ }^{\circ} 2760$ ). En segundo lugar, esta encuesta constituye un estudio monográfico sobre JT, lo que nos proporciona información detallada sobre la actitud de los españoles ante diversas medidas de JT (fundamentalmente, comisiones de la verdad, juicios y reparaciones simbólicas), así como acerca de un buen número de variables independientes y de control. Esta información tan pormenorizada constituye un valioso punto de partida para llevar a cabo un análisis exhaustivo sobre las actitudes de la población española ante este tipo de medidas, dejando de lado la abundante -e imprecisa- especulación política y mediática sobre las mismas

A nivel teórico, este artículo contribuye a un mejor conocimiento de la JT al plantear un conjunto de hipótesis sobre los determinantes de las actitudes individuales hacia estas políticas, basadas en parte en la literatura sobre JT, pero también en las investigaciones sobre el trauma, la victimización y la transmisión intergeneracional de identidades. El artículo se organiza del siguiente modo: en primer lugar, se presenta el caso español y se expone brevemente la importancia que tiene analizar la justicia transicional y postransicional en este país. En segundo lugar, se presenta el marco teórico y las hipótesis que se deducen del mismo. A continuación se analizan los resultados y se discuten sus implicaciones.

\section{LA JUSTICIA TRANSICIONAL EN ESPAÑA ${ }^{4}$}

El caso español es especialmente interesante para llevar a cabo una investigación sobre las actitudes de los ciudadanos hacia diversas medidas de JT. Son bien conocidas la brutalidad y las prolongadas injusticias que perpetró el franquismo contra quienes perdieron la guerra civil, así como con quienes negaron posteriormente a cumplir con sus dictados. Durante el conflicto civil, decenas de miles de personas de ambos bandos perdieron la vida a causa de ejecuciones, fundamentalmente extrajudiciales. Sin embargo, la

\footnotetext{
${ }^{3}$ Las excepciones más notables se encuentran en las investigaciones de Gibson (2002; 2004a; 2004b) sobre Sudáfrica y en las de Nalepa $(2008 ; 2010)$ sobre Hungría, Polonia y la República Checa. Véase también Thoms et al. (2008).

${ }^{4}$ Entre las reflexiones sobre la JT en España desde el punto de vista jurídico destacan Chinchón (2007) y Gil (2009).
} 
violencia política se prolongó a lo largo de toda la dictadura, particularmente durante la posguerra; se estima que el régimen de Franco ejecutó aproximadamente a 50.000 personas, que el número de prisioneros recluidos en campos de concentración franquistas ascendió a 300.000 y que cientos de miles de personas se vieron forzadas al exilio tras la guerra civil. Además el franquismo se negó a que recuperaran sus puestos de trabajo decenas de miles de personas que habían sido depuradas por sus inclinaciones ideológicas, y se negó a ofrecer pensiones o cualquier tipo de compensación a los veteranos de guerra, a los civiles discapacitados, y a las viudas y huérfanos de los combatientes del bando perdedor. De un modo similar, los bienes y propiedades de partidos políticos, sindicatos y particulares fueron confiscados por el mero hecho de haber simpatizado con la Segunda República. En contraste, aquéllos que habían respaldado a los vencedores gozaron de todo tipo de privilegios, prebendas y reconocimiento.

Tras el fallecimiento de Franco, la presencia de la memoria traumática de la guerra civil y del deseo obsesivo de evitar su repetición, animó a los principales actores políticos y a la mayoría de los ciudadanos españoles a mirar al futuro dejando de lado los aspectos más espinosos del pasado. Existía (y, entre amplios sectores de la sociedad, aún existe) la creencia firme de que éste era el único modo de garantizar una transición pacífica a la democracia (Aguilar 2008a). También hay que recordar que, en aquellos momentos, aunque sí que existían medidas de reparación destinadas a las víctimas de violencia política, no había políticas tan articuladas como las que se contemplan en la literatura posterior sobre JT y tampoco organismos internacionales encargados de ejercer presión sobre los países para evitar que sus procesos de democratización se llevaran a cabo garantizando la impunidad de los responsables de los crímenes cometidos en el pasado. En este contexto, el Parlamento promulgó la Ley de Amnistía de 15 de octubre de 1977, que disponía, entre otras cosas, la liberación de los presos con responsabilidades políticas y salvaguardaba el pasado dictatorial de cualquier tipo de proceso judicial.

Entre el abanico de posibles medidas de reparación que podrían haberse adoptado durante la transición a la democracia, al principio predominaron abrumadoramente las políticas de reparación material (fundamentalmente pensiones) dirigidas a los vencidos de la guerra civil y a sus familiares (Aguilar 2008a:506-515). Aunque este tipo de políticas se fue ampliando y mejorando al cabo del tiempo, el conjunto siempre resultó algo limitado y fragmentario. Además, otras posibles medidas de JT como la condena oficial de la dictadura, políticas simbólicas dirigidas a rendir homenaje a todas las víctimas del franquismo, la creación de comisiones de la verdad o la anulación de los juicios franquistas -por no mencionar la realización de un proceso judicial contra los responsables de violaciones de derechos humanos bajo la dictadura- nunca se llevaron a cabo. Y, cuando la mayoría de españoles pensaba que los episodios más dolorosos de su historia habían sido sepultados en el olvido, el pasado irrumpió de nuevo con fuerzas 
renovadas: en 2000, fecha en la que aún yacían sin identificar varios miles de víctimas pertenecientes al bando republicano inhumadas en fosas comunes, una asociación privada dedicada a la localización y exhumación de fosas comunes de la guerra civil o el periodo inmediatamente posterior (la Asociación para la Recuperación de la Memoria Histórica, ARMH) contribuyó a desencadenar un debate político, mediático y social sobre las carencias de las políticas previas de $\mathrm{JT}^{6}$.

En este contexto, las fuerzas sociales y políticas conservadoras se posicionaron en contra de "hurgar en el pasado". Por el contrario, los partidos y asociaciones sociales progresistas sostuvieron que había llegado el momento de ofrecer a las víctimas de la guerra y la dictadura una reparación adecuada. El salto adelante más importante en relación con las medidas de JT tuvo lugar durante la legislatura 2004-2008, especialmente con la aprobación de la Ley 52/2007 de 26 de diciembre, que "reconoce y amplía los derechos y establece medidas en favor de quienes padecieron persecución durante la guerra civil y la dictadura" 7 .

La encuesta en la que se basa este artículo se llevó a cabo inmediatamente después de la aprobación de esta ley. Un $62 \%$ de los entrevistados afirma conocer esta medida y a más de un $50 \%$ de éstos le parece que esta norma está "muy bien" o "bien". Adicionalmente, un $41 \%$ considera que era una "medida necesaria, pues la democracia tenía una deuda pendiente con las víctimas de la guerra civil y del franquismo". A pesar de toda la controversia que suscitó el proyecto de ley, sólo un $27,6 \%$ piensa que "no es una medida oportuna, pues resucita rencores del pasado", mientras que menos personas aún (un $13,2 \%$ ) estiman que "es una medida que se queda corta, pues no hace verdadera justicia a las víctimas de la guerra civil ni a las del franquismo".

Aunque en muchas ocasiones se ha hecho referencia al tiempo transcurrido desde el final de la guerra y del franquismo para deslegitimar la oportunidad de los debates públicos en torno a las medidas de JT, nuestra encuesta sugiere que prácticamente ningún español permanece indiferente ante el recuerdo de estos eventos históricos. Obsérvese, por ejemplo, la escasa importancia de las "no respuestas" dadas a la pregunta "iqué sentimiento le provoca a usted pensar en la guerra civil y en el franquismo?", dando al entrevistado dos opciones, según el orden de importancia que atribuya a las mismas (ver gráficos A.1). Los sentimientos que predominan son la "tristeza", la "rabia" y la "incomprensión", tanto en lo relativo a la guerra civil como al franquismo. Sin embargo, la "tris-

\footnotetext{
${ }^{5}$ El debate resurgió a causa de varios factores, uno de los cuales tuvo una importancia crucial: la llegada a la esfera pública de los "nietos de la guerra", desprovistos del sentimiento de culpa y del miedo de sus mayores y, por lo tanto, mucho más dispuestos a afrontar estos asuntos de forma abierta (Aguilar 2008a).

${ }^{6}$ Es cierto que al principio de la democracia se exhumaron fosas comunes de la época de la guerra civil, pero sólo se trató de unos pocos casos aislados. Entonces, no se produjo nada parecido a un debate político o social sobre la pertinencia de extender esa práctica a otras partes del país y, finalmente, según Emilio Silvia, el principal promotor de la ARMH, dichas exhumaciones se detuvieron tras la intentona golpista del 23-F.

${ }^{7}$ Boletín Oficial del Estado n. ${ }^{0}$ 310, de 27 de diciembre de 2007, p. 53.410. Las principales medidas que contiene esta ley están descritas en Aguilar (2008b).
} 
teza" es el sentimiento más frecuente en el primer caso, mientras que la rabia lo es en el segundo.

Y, lo que resulta más significativo aún, cuando se pregunta por cuál es el acontecimiento de la historia de España que al entrevistado le parece más significativo, y no se ofrece ninguna categoría de respuesta (se trata, por lo tanto, de un recuerdo espontáneo), la mayoría elige el golpe de Estado de 1936 y la subsiguiente guerra civil. Y aunque en el momento que se les ofrecen categorías de respuesta concretas un $40 \%$ considera que la transición a la democracia es el suceso más importante de nuestra historia, un $20,5 \%$ sigue eligiendo la guerra civil. Adicionalmente, en otra pregunta, un $53,1 \%$ considera que el recuerdo de la guerra civil continua muy vivo en la memoria de los españoles, un $45,6 \%$ cree que es falso que se hayan olvidado los rencores y las divisiones que creó esta contienda y un $57,5 \%$ piensa lo mismo del franquismo.

Finalmente, por lo que se refiere a la oportunidad de aprobar acciones de JT durante la legislatura anterior, cuando se desciende a las medidas concretas, la mayoría de los ciudadanos no sólo aprueban las contempladas en la ley de 2007 (por ejemplo, el $50,2 \%$ piensa que los restos de las víctimas de la guerra civil "deberían identificarse y ser trasladados a un cementerio" y un $55, \%$ cree que los símbolos que exaltan la guerra civil deberían ser retirados de los lugares públicos), sino que, en algunos casos, habrían sido partidarios de llegar aún más lejos, pues consideran que es el Estado el que debería encargarse de recuperar e identificar los restos de las fosas comunes (el $84 \%$ de los partidarios de trasladar los restos), que la democracia debería anular los juicios políticos que tuvieron lugar bajo el franquismo $(50 \%)$ y que debería haber un monumento dedicado a todas las víctimas de la dictadura $(61 \%)$.

\section{MARCO TEÓRICO}

¿Cuáles son los determinantes de las diferencias que muestran los españoles ante las diversas medidas posibles de JT? En primer lugar, podría pensarse que, por encima de todo, ciertas características individuales, como la ideología, deberían influir en dichas opiniones: es plausible pensar que los simpatizantes de la izquierda fueran más favorables a la ley que promovía el partido socialista gobernante. Asimismo, dada la identidad derechista de la dictadura franquista, la reparación de sus víctimas podría considerarse una medida "izquierdista". En segundo lugar, la mayor parte de la población española no ha experimentado personalmente la guerra civil, lo que puede conllevar diferencias en las posiciones de los ciudadanos en función de su edad. Los menores de 30 años ni siquiera han vivido la dictadura. Para éstos, las experiencias de victimización registradas en su familia sólo serán relevantes si ha habido una transmisión intergeneracional de lo que podemos denominar "conciencia de víctima". En tercer lugar, dado que las políticas de reparación más innovadoras y llamativas de la ley de 2007 no consistían en compensaciones monetarias para las víctimas, el interés material resultaría un tanto irrelevante 
en este contexto. Finalmente, los factores contextuales también podrían desempeñar un papel importante; en particular, sería plausible que los habitantes de algunas regiones tuvieran diferentes perspectivas sobre la JT dadas las diferencias que existen entre ellas en la interpretación de sus historias y recuerdos colectivos de las últimas décadas.

Como se verá a continuación, en este artículo sostenemos que las actitudes hacia la JT están determinadas por una combinación de factores individuales, familiares y contextuales (en este caso, regionales).

\section{Factores individuales}

Las características individuales son esenciales para explicar la variación existente en las opiniones sobre la política. En este artículo nos concentramos únicamente en las que juzgamos más relevantes desde el punto de vista teórico: la edad del individuo es, obviamente, un factor relevante para explicar sus opiniones políticas. En cuanto a las medidas de JT, si las atrocidades tuvieron lugar en un pasado no reciente, cabría esperar que los individuos de edad avanzada fueran más reticentes a respaldarlas por su proximidad personal a los eventos traumáticos. El mecanismo causal al que hacemos referencia es el miedo, que puede tener un carácter más o menos específico: por una parte, las personas pueden tener un temor concreto a las represalias de aquellos que se verían afectados negativamente por estas políticas, como los antiguos "victimizadores". Por otra parte, la gente puede tener un temor general al retorno del conflicto.

En coherencia con este peso explicativo del miedo, observamos que las reticencias que los españoles puedan haber tenido en el pasado a recordar en público las trayectorias vitales de su familia durante la contienda y la dictadura parecen, sin haber llegado a desaparecer, haberse ido diluyendo con el paso del tiempo. Si estudiamos las respuestas sobre el recuerdo de participación familiar en la guerra civil en distintas encuestas llevadas a cabo entre los años 1980 y 2008 (Gráfico A.2), Ilama la atención el poderoso descenso de los que dicen no conocer la respuesta, y también el incremento del porcentaje de encuestados que reconocen alguna vinculación familiar con el bando republicano, paralela a la reducción de los que sólo reconocen conexiones con el bando nacional. Consideramos que esto último podría ser debido, entre otras razones, a una mayor sinceridad en las respuestas, que estaría relacionada con esta paulatina disminución del miedo ${ }^{8}$. Con todo, no deja de ser sorprendente que, según esta encuesta,

\footnotetext{
${ }^{8}$ En esta encuesta se pregunta, por primera vez, cuál es el bando que el entrevistado considera que provocó más muertes durante la guerra civil; mientras que un $36 \%$ piensa que "los dos por igual", un 30\% cree que el bando nacional, mientras que sólo un $4 \%$ opta por culpabilizar al bando republicano. Por lo tanto, aunque aún son mayoría los que reparten las culpas por igual entre ambos contendientes, parece que cada vez son más los que no comparten la idea de que "todos fuimos igualmente culpables por las atrocidades cometidas en la guerra civil". También se pregunta qué bando fue el principal responsable de que estallara la guerra civil; un $40 \%$ cree que ambos, un $30 \%$ que "las derechas", mientras que sólo un $6,7 \%$ culpabiliza a "las izquierdas". Lo que acabamos de exponer seguramente obedece a que el enorme desarrollo que ha expe-
} 
un 30,5\% de los españoles aún piense que "en España todavía hay miedo a hablar del pasado".

Por otra parte, las personas pueden temer de forma general un nuevo conflicto 0 el advenimiento de otro régimen autoritario. Mientras que se puede afirmar que la proximidad personal a los eventos traumáticos también podría fomentar el deseo de reparaciones (y, como veremos, este debería de ser el caso de quienes fueron víctimas o familiares de las mismas), cabría esperar que la aversión al riesgo fuera generalmente alta entre aquéllos que han sido testigos del conflicto civil o de la dictadura'. Además, en cuanto al miedo específico a las represalias, podemos esperar que tenga un impacto diferente en las preferencias individuales en función de factores contextuales como el tamaño del municipio en el que habita el individuo: en municipios grandes, el anonimato es mayor que en las poblaciones pequeñas Aguilar (2008a); en éstas, la política está más personalizada y es más fácil que las personas sientan que las políticas de reparación pueden tener consecuencias específicas sobre su vida cotidiana ${ }^{10}$.

El modo en que los individuos evalúan las medidas de JT debería estar claramente determinado por su capacidad de comprender no solamente el pasado en general, sino también acontecimientos históricos clave. La educación es, probablemente, la característica individual más importante para explicar diferencias en estas aptitudes. No obstante, es posible que ésta no sea la única característica relevante: el interés por la política también puede desempeñar un papel en la capacidad de evaluar dichas medidas. Asimismo, como ya se ha comentado, cabe esperar que los individuos tengan opiniones distintas sobre la JT según el lugar en el que se sitúen a sí mismos en la escala ideológica. La dirección del efecto dependerá de la historia del país, incluida la trayectoria de los partidos políticos. Finalmente, la religiosidad y/o la identidad nacional conforman otras características individuales a considerar, en la medida en que la victimización afectó a las personas en función de sus creencias religiosas y de sus adscripciones identitarias de un modo desigual; en otras palabras, si la victimización tuvo un componente religioso y/o nacionalista.

rimentado en los últimos años la investigación sobre la represión en la guerra y en la posguerra ha venido a demostrar que los nacionales cometieron más atrocidades que los republicanos durante la contienda, así como a poner sobre la mesa todas las dimensiones represivas de la dictadura que vino después. La diferencia de algo más de $25 \%$ puntos entre la culpabilidad atribuida a cada uno de los dos bandos también podría explicar que la sociedad se haya venido mostrando crecientemente más reacia a reconocer que su familia combatió con el bando nacional.

${ }^{9}$ Sobre el miedo causado por la represión en regímenes autoritarios véase, por ejemplo, Koonings y Kruijt (1999).

${ }^{10} \mathrm{En}$ poblaciones pequeñas, las responsabilidades personales por atrocidades del pasado pueden atribuirse con más facilidad, lo que dificulta el debate sobre el pasado (Aguilar 2008a). 


\title{
Factores familiares y de socialización
}

Resulta comprensible que los sociólogos centraran tradicionalmente su atención en el impacto de las opiniones y valores familiares en la formación de las percepciones de los individuos sobre varios aspectos de la vida. La literatura sobre la transmisión intergeneracional de opiniones políticas experimentó un rápido crecimiento en la década de los setenta, cuando Styskal y Sullivan (1975:516-7) concluían:

\begin{abstract}
"Los padres, los individuos a los que una persona más reverencia y en los que más confía en los primeros años de su vida, son la fuerza más importante en la transmisión de una identificación partidista. [...] La elección de un partido, el significado sustantivo del partido para el individuo y la orientación del individuo hacia los diversos temas son en mayor medida productos de las lealtades derivadas de los padres en un estadio temprano de la vida de una persona, cuando los procesos cognitivos se encuentran relativamente subdesarrollados".
\end{abstract}

De hecho, a pesar de la creencia popular según la cual en la adolescencia los hijos se alejan de sus padres en busca de una guía alternativa para orientarse en materia de valores, la mayor parte de la investigación empírica revela una concordancia sorprendente entre las visiones del mundo de padres e hijos (adultos) (Acock y Bengtson 1980; Jennings y Niemi 1981; Miller y Glass 1989; Dalhouse y Frideres 1996). Por lo tanto, cabría esperar cierta alineación entre las posiciones de los individuos y las de sus padres. Según nuestra hipótesis, también la conciencia de víctima podría haber sido transmitida de una generación a la siguiente.

Los efectos psicológicos de la violencia (la tortura, la violencia sexual o el encarcelamiento) y otras formas de victimización se han analizado ampliamente en la literatura académica sobre los conflictos. No obstante, el estudio del efecto específico de experiencias traumáticas en las identidades y en el comportamiento político de los individuos generalmente se ha pasado por alto (Balcells 2007). En parte, la razón radica en la tradicional falta de datos disponibles para realizar el análisis empírico adecuado. Pese a que el desarrollo reciente de encuestas y experimentos en contextos de posguerra ha generado un incremento de los estudios empíricos que abordan estas cuestiones, la base empírica sigue siendo bastante fragmentaria. Asimismo, ésta se refiere en su mayor parte a los efectos a corto plazo de los acontecimientos traumáticos (Balcells 2007). No constatamos que el estado de la cuestión sea mucho mejor en lo relativo a la experiencia de los individuos con las dictaduras y a sus preferencias y opiniones posteriores, durante los procesos de democratización y después de éstos. Normalmente, esta literatura se ha centrado en el papel de activistas políticos o individuos altamente comprometidos (Maravall 1978), mientras que sólo algunos desarrollos recientes se han referido a individuos comunes (Wittenberg 2006).

Por consiguiente, la literatura existente no puede dar respuesta a la pregunta de si la victimización genera consecuencias a largo plazo en las actitudes que podrían 
traducirse en el apoyo a medidas de JT. No obstante, podemos afirmar que, dado que la victimización en primera persona conduce a respaldar las políticas de reparación a corto plazo, (Nalepa 2007; Theidon 2006; Gibson 2002; 2004a; 2004b; 2007; Biro et al. 2004), la victimización de familiares en tiempos de guerra o dictadura incrementará la propensión a manifestar actitudes favorables a las políticas de reparación. El mecanismo que conduce a la transmisión intergeneracional de estas actitudes debería ser el mismo que explicara la transmisión intergeneracional de las identidades políticas.

La transmisión de la condición de víctima podría disminuir con el paso del tiempo, de forma que entre los encuestados más jóvenes podría ser menor el porcentaje de los que tienen recuerdos de victimización en el seno de su familia. Este parece haber sido el caso, aunque el porcentaje de quienes responden NS/NC a las preguntas sobre victimización es, como máximo, de un $35 \%$ en la cohorte más joven (véase el gráfico A.3). En otras palabras, si bien entre los mas jóvenes existe un mayor grado de desmemoria de victimización familiar, el recuerdo es, con todo, bastante elevado.

\section{Factores contextuales}

La literatura sobre socialización ha constatado que la familia no es la única fuente de socialización de los individuos, ya que las experiencias de resocialización posteriores pueden erosionar los efectos de la socialización primaria de los padres ${ }^{11}$. El contexto en el que el individuo vive, trabaja y las relaciones que establece con otras personas es también susceptible de influir en las actitudes hacia las medidas de JT. Los factores contextuales, así como los mecanismos por los cuales operan, pueden ser variados y complejos. La comunidad política del individuo (su localidad o región) es tan sólo un ejemplo: en ella interactúa el individuo de acuerdo con un conjunto compartido de repertorios culturales que se benefician de un refuerzo grupal. Así, si los ciudadanos de una región o localidad concreta hubieran sido victimizados de un modo diferenciado, sería plausible pensar que en su conjunto mostrarán actitudes más favorables hacia las políticas de JT.

${ }^{11}$ Beck y Jennings (1991:759) y Martín (2004). 


\section{ANÁLISIS EMPíRICO}

Los datos generados por nuestra encuesta, con una muestra de 2936 entrevistados en el conjunto del país ${ }^{12}$, permite medir el respaldo dado a tres tipos distintos de posibles medidas de JT: (1) la creación de "comisiones de la verdad" para investigar los abusos pasados; (2) la organización de "procesos judiciales" para juzgar a los responsables de dichos abusos; y (3) las "reparaciones simbólicas", es decir, la retirada de símbolos que rinden tributo a Franco o al franquismo. De acuerdo con una práctica común en la literatura ${ }^{13}$, se ha operacionalizado el respaldo a estas políticas mediante las siguientes preguntas:

1) Por lo que se refiere a las actitudes relativas a la creación de una comisión de la verdad: "En su opinión, ¿debería crearse una Comisión de Investigación, independiente del Gobierno, para investigar las violaciones de derechos humanos que tuvieron lugar durante el franquismo?"14

2) En cuanto a las actitudes hacia los procesos judiciales por atrocidades cometidas en el pasado: "¿Las autoridades que violaron derechos humanos bajo el franquismo, deberían ser llevadas a juicio?"15

3) En cuanto a las actitudes hacia las reparaciones simbólicas, usamos las respuestas (de acuerdo/en desacuerdo) registradas en el ítem siguiente: "Los símbolos que rinden homenaje a Franco y al franquismo, deben ser retirados de los lugares públicos".

Para poner a prueba nuestras hipótesis, incluimos tres grupos de variables independientes y de control en un conjunto de regresiones logísticas de tipo "paso a paso" binarias y logísticas. Un primer conjunto de variables independientes miden las "características individuales": (1) 'Edad': se espera que los encuestados de edad avanzada se muestren más reticentes a las medidas de JT. Como ya se ha comentado, también podemos esperar que tenga lugar algún tipo de interacción entre la edad y el tamaño de la localidad de residencia del encuestado, debido al anonimato que proporcionan los vecindarios de mayor tamaño. (2) 'Interés por la política'16: es probable que la exposición al debate público alrededor de la ley de 2007 fomente la adopción de posturas claras al respecto.

${ }^{12}$ El País Vasco y Cataluña están sobrerrepresentadas, con 699 y 683 encuestados, respectivamente. Siempre que presentemos resultados para el conjunto de la población española, estas muestras estarán ponderadas.

${ }^{13}$ Nalepa (2007; 2010); Biro et al. (2004).

${ }^{14}$ Las categorías de respuesta son $1=$ "si"; 2 = "no".

151 = "completamente en desacuerdo"; 3 = "completamente de acuerdo".

${ }^{16}$ Usamos la pregunta: "¿Podría decirme si Ud. se interesa mucho, bastante, poco o nada por la política en general?" (4= mucho; $1=$ nada). 
Esta variable se incluye como control ${ }^{17}$. (3) 'Educación'18: incrementa la sofisticación del individuo $\mathrm{y}$, por consiguiente, su capacidad para formarse sus propias opiniones sobre cualquier acontecimiento; también se incluye como variable de control. (4) 'Religiosidad'19: la fractura ("clivaje") religiosa fue muy relevante durante la guerra civil y la posterior dictadura -los miembros del clero fueron víctimas de la violencia izquierdista durante el conflicto y la Iglesia católica se alineó con Franco tanto durante la contienda como bajo la dictadura. Por todo ello cabe esperar que la religiosidad tenga un impacto negativo en el respaldo a las medidas de $\mathrm{JT}^{20}$. (5) 'Ideología'21: al igual que la religiosidad, cabe esperar un claro efecto negativo de una ideología de derecha en el apoyo a las políticas de $\mathrm{JT}^{22}$.

Se incluye un segundo conjunto de variables a modo de proxies de las características familiares y la "socialización": (1) 'Identidad familiar durante la guerra civil'23. aquéllos cuya familia se había identificado con los nacionales durante la guerra civil deberían mostrarse más reticentes respecto a las políticas de JT, y viceversa. (2) 'La familia hablaba de política'24. Esta variable se incluye como control: el grado en que se hablaba de política en casa debería de influir en la transmisión intergeneracional de las identidades y la victimización. (3) 'Ideología del padre':25 se espera que el hecho de tener un padre con una ideología de derechas tenga un impacto negativo en el apoyo a las medidas de JT. (4) 'Victimización individual/familiar': se tiene en cuenta la victimización, tanto a manos del bando franquista en la guerra civil como por parte de la dictadura de Franco. Se espera que aquellas personas que han sido víctimas, tanto personalmente como indirectamente -a través de su familia-se muestren más favorables a las políticas

${ }^{17}$ El nivel educativo y el interés por la política son controles obligatorios en nuestra estimación, dado que los individuos con una puntuación mayor en una u otra tienen una probabilidad más baja de dar una respuesta del tipo "no sabe".

181 "educación primaria o menos"; 2 "educación secundaria"; 3 "titulación universitaria".

${ }^{19}$ Se trata de una variable escalar de 1 a 6: 1 = "no religioso"; 6 = "muy religioso".

${ }^{20} \mathrm{El}$ impacto de la religión en la política española no es tan intenso como lo era en el pasado, aunque sea aún apreciable (Montero et al. 2008).

${ }^{21}$ Posicionamiento subjetivo en la escala izquierda-derecha, con valores que van del 1 (extrema izquierda) al 10 (extrema derecha).

${ }^{22}$ Incluso podría ocurrir que algunas personas de derechas hubieran sido reparadas por la dictadura como consecuencia de sus experiencias de victimización durante la guerra civil.

${ }^{23}$ Se mide con la pregunta: "¿con cuál de los dos bandos de nuestra última guerra civil simpatizaba más su familia: con los nacionales o con los republicanos?" La tasa de respuesta a esta pregunta fue del $77 \%$. Se incluyen en los modelos dos variables dicotómicas: 'Familia del bando nacional' y 'Familia del bando republicano'.

${ }^{24}$ ¿¿Recuerda cuánto solía hablarse de política en su casa cuando era niño o adolescente?" (4= mucho; $1=$ nada).

${ }^{25}$ La correlación entre la ideología del padre y la de la madre es de 0,77 . Al optar por la del padre reflejamos la preeminencia del varón en la cultura española tradicional. Si se usara la de la madre, como han comprobado los autores de este artículo, los resultados no variarían. 
de $\mathrm{JT}^{26}$. Asimismo, se espera que el efecto de la victimización aumente con la edad del encuestado, algo que pondremos a prueba usando interacciones entre estas variables. Las dos variables incluidas en las regresiones son: (4.a) 'Víctimización durante la guerra civil': variable dicotómica con valor 1 si el encuestado afirma que él o su familia fueron víctimas del bando franquista durante la guerra civil, y valor 0 si no lo hace ${ }^{27}$; (4.b) 'Víctimización durante la dictadura': variable dicotómica con valor 1 si el encuestado afirma que él mismo o algún miembro de su familia sufrieron persecución durante la dictadura franquista, valor 0 si no lo hace ${ }^{28}$.

Finalmente, hay un conjunto de variables dirigidas a medir los "factores contextuales". Como es bien sabido, la dictadura franquista reprimió con dureza algunas manifestaciones de las minorías culturales y lingüísticas de España. Dado que nuestra encuesta dispone de submuestras representativas para el País Vasco y Cataluña, dos territorios con una identidad nacional diferenciada y un sentimiento colectivo de victimización más acentuado que otras, incluimos sendas variables dicotómicas en las regresiones. Esperamos que ambas tengan un efecto positivo en el respaldo a las medidas de JT.

En los gráficos A.4, puede observarse la distribución de las respuestas correspondientes a los diferentes ítem que constituyen las tres variables dependientes del análisis: la creación de una comisión de la verdad que investigue las violaciones de los derechos humanos durante el franquismo ("Comisiones de la verdad"), la organización de procesos judiciales para juzgar a los responsables de las violaciones de los derechos humanos durante el franquismo ("Juicios") y la retirada de los espacios públicos de los símbolos que rindan tributo a Franco y al franquismo ("Símbolos").

Estos gráficos indican que, excepto en el caso de nuestra primera variable dependiente (comisiones de la verdad), los españoles están claramente a favor de las políticas de JT. Esta primera constatación resulta interesante ya que la vehemencia con la que ciertas formaciones políticas y medios de comunicación se opusieron a que se reabriera un debate sobre el pasado podría hacer esperar un mayor nivel de oposición a este tipo de políticas en el conjunto de la sociedad. Asimismo, observamos que los encuestados son más proclives a estar de acuerdo con las reparaciones de tipo simbólico que con las otras dos medidas de JT; por otro lado, soprendentemente, los juicios reciben un respaldo mayor que las comisiones de la verdad.

La Tabla A.1 muestra los resultados del análisis de regresión logística paso a paso de la variable "comisión de la verdad". El Modelo 1 sólo incluye los factores individuales; el Modelo 0 incorpora un término de interacción entre la edad y el tamaño del municipio

\footnotetext{
${ }^{26}$ Debido al limitado número de víctimas que figuran en la encuesta decidimos unir las experiencias familiares e individuales en una sola variable.

${ }^{27}$ Las categorías de respuesta son: muerte en combate o bombardeo; asesinato, pena de muerte; desaparición; encarcelamiento; huída de España; tuvo que esconderse; fue despedido del trabajo.

${ }^{28}$ Las categorías de respuesta son: detención; encarcelamiento; despido del trabajo; abandono del país; ejecución.
} 
que debería permitirnos captar los efectos variables de la edad condicionados por el nivel de anonimato en el que de desenvuelven, de forma cotidiana, los individuos. Esta interacción no se incluye en los modelos restantes. Los Modelos 2 al 4 añaden la socialización y los factores familiares al Modelo 1. En el Modelo 4 se incluye otra interacción entre la edad y la victimización. El Modelo 5 incorpora variables relacionadas con el contexto.

El Modelo 0 de la tabla A.1 revela un interesante resultado que confirma nuestras expectativas iniciales respecto a la interacción entre la edad del encuestado y el tamaño del municipio. El principal efecto de la edad es negativo, lo que significa que cuanto mayor es la edad del entrevistado, menor es la probabilidad de que acepte la creación de comisiones de la verdad. No obstante, el principal efecto de la edad cambia de acuerdo con el tamaño del municipio, dependiendo de si se trata de una localidad pequeña o de una gran ciudad: las personas de edad avanzada de las grandes ciudades se muestran menos reticentes a la creación de comisiones que las que viven en poblaciones pequeñas (de hecho, la variable de tamaño del municipio indica que, independientemente de la edad, cuanto más pequeño es el municipio, más reticente se es a respaldar las comisiones). Una vez más, puede explicarse por el miedo a las consecuencias de aplicar estas medidas en localidades más pequeñas y, por lo tanto, en las que menos sencillo resulta preservar el anonimato. No obstante, este efecto interactivo desaparece al introducir otras variables de control en el nivel individual, especialmente las que hacen referencia al posicionamiento subjetivo en la escala izquierda-derecha y la religiosidad.

El Modelo 1 ha confirmado nuestras expectativas básicas acerca de las variables de tipo individual. El efecto de la edad vuelve a ser negativo y estadísticamente significativo; tanto la religiosidad como la ideología muestran un impacto negativo con la probabilidad de aceptar las comisiones, lo que significa que cuanto más religiosa y de derechas es la persona, más reticente es a esta medida de JT. Por otra parte, resulta sorprendente que la educación, así como el interés por la política no tengan un efecto estadísticamente significativo.

El Modelo 2 analiza el impacto de los factores familiares e ideológicos. Podemos aquí confirmar que, tal y como se esperaba, aquellos individuos cuyas familias se alinearon con el bando nacional durante la guerra civil son significativamente menos proclives a aceptar las comisiones. No hay diferencias en la propensión de los individuos cuyas familias se encontraban en el bando republicano y aquellos cuyas familias estaban divididas y luchaban en ambos bandos. Por consiguiente, en cuanto a sus historiales familiares, los individuos son significativamente menos susceptibles a aceptar el establecimiento de comisiones si provienen de una familia con un pasado homogéneamente nacional; que un individuo tenga al menos parte de su familia en el bando republicano incrementa el grado de aceptación de esta medida. La ideología del padre no influye en la variable dependiente, aunque la estimación tiene el signo previsto (negativo).

Un resultado interesante de este modelo es la mayor probabilidad de que los individuos apoyen la creación de comisiones cuando la familia hablaba de política con frecuencia en casa. Podría interpretarse como una prueba que confirma la importancia de 
la socialización en la elaboración de actitudes hacia la JT. Sin embargo, este efecto se reduce en las especificaciones posteriores del modelo, especialmente tras incluir información sobre la victimización.

El Modelo 3 analiza las hipótesis referentes a la victimización. Es interesante constatar que ésta no parece una experiencia homogénea. La victimización a manos del ejército franquista en la guerra civil no influye en la variable dependiente. No obstante, los individuos que manifiestan haber sido victimizados durante el franquismo tienen una probabilidad más alta de aceptar las comisiones; la magnitud de este efecto, estadísticamente muy significativo, es bastante grande. Por consiguiente, la victimización parece más relevante si los abusos tuvieron lugar recientemente (en la dictadura) que si ocurrieron en la guerra. Este resultado tiene mucho sentido si se tiene en cuenta que las comisiones de la verdad se centrarían en las violaciones de los derechos humanos cometidas durante la dictadura, no en la contienda.

Como se anunció, se ha incluido un término de interacción entre la victimización declarada y la edad (Modelo 4). Se esperaba que el impacto significativo de la victimización fuera menor entre los jóvenes. Sin embargo, no podemos confirmar totalmente esta conjetura, porque la interacción no es estadísticamente significativa (aunque tiene un signo positivo). Parece pues que la victimización se transmite en gran medida a las nuevas generaciones: su influencia, que es positiva y estadísticamente muy significativa, no cambia con la edad del entrevistado. Asimismo, el efecto de la variable principal de edad se mantiene. Finalmente, el Modelo 5 indica que los encuestados catalanes no difieren de los de otras regiones en la propensión a aceptar las comisiones; los vascos, en cambio, tienen una probabilidad mayor de defender este tipo de medidas.

La tabla A.2 expone los resultados para la variable dependiente "juicios". El Modelo 0 no puede confirmar plenamente nuestra hipótesis respecto al efecto diferenciado de la edad en poblaciones pequeñas y grandes ciudades, ya que la interacción no es estadísticamente significativa. El Modelo 1 resulta bastante coherente con el mismo modelo expuesto en la tabla A.1, ya que confirma la significatividad de las siguientes variables individuales: ideología y religiosidad; en esta ocasión, el interés por la política tampoco resulta significativo. Sin embargo, a diferencia de lo que ocurría en la Tabla A.1, ahora la educación también es significativa: cuanto mayor es el nivel educativo del entrevistado, menor es su apoyo a las medidas de TJ.

El Modelo 2 revela otras diferencias respecto a lo observado en la tabla A.1. Provenir de una familia que luchó con los republicanos en la contienda incrementa la probabilidad de apoyar la celebración de juicios; también ocurre lo contrario: aquellos entrevistados cuyas familias se alinearon con los franquistas en la guerra son significativamente menos partidarios de los procesos judiciales.

El Modelo 3 desmiente que la victimización tenga un impacto general en la probabilidad de estar a favor de llevar a juicio a los antiguos perpetradores de estos delitos, ya que ninguna de las variables de victimización es significativa. No obstante, el Modelo 4 revela una interacción significativa entre la edad y la victimización a manos del régimen de Franco: sólo los entrevistados de edad avanzada que se declaran victimizados 
están a favor de esta medida. Los encuestados que no se declaran víctimas rechazan claramente la puesta en marcha de procesos judiciales. Por otra parte, los jóvenes que se declaran victimizados también están en contra de esta medida, lo que indica que, de hecho, las experiencias de victimización pueden conducir a actitudes distintas respecto a las medidas de reparación de acuerdo con la edad del encuestado. Los que no tienen experiencias directas de victimización, pero sí indirectas (a través de sus antepasados), se muestran menos reticentes a este tipo de reparaciones.

Las variables regionales son significativas. Los encuestados del País Vasco y Cataluña tienen una probabilidad más alta de aceptar que se lleven a cabo juicios que los encuestados de otros territorios, aunque el efecto es más acentuado en el primer caso que en el segundo.

En la tabla A.3 se estudia una de las posibles medidas de reparación simbólica: retirar los símbolos del franquismo existentes. Como en los casos precedentes, se confirma que, a pesar de que los entrevistados de edad avanzada generalmente son más reticentes a las reparaciones de carácter simbólico, aquéllos que viven en áreas urbanas más pobladas no lo son tanto. Asimismo, las únicas variables sociodemográficas importantes, además de la edad, son el posicionamiento ideológico y la religiosidad. No obstante, el posicionamiento de los entrevistados parece depender en gran medida de nuestro bloque de variables familiares (Modelo 2). Existe una asociación casi lineal entre la trayectoria familiar en el conflicto civil y las actitudes de los encuestados respecto a esta medida. Si el encuestado menciona que su familia tiene un pasado franquista, su probabilidad de aceptar esta forma de reparación simbólica se reduce notablemente en comparación con aquéllos que manifiestan tener vínculos en ambos bandos. Cuando el individuo procede de una familia que luchó en el bando republicano, es más probable que la acepte que si tuviera a sus familiares divididos entre ambos bandos. La victimización también parece importante en relación con nuestra variable dependiente. Cabe destacar que en esta ocasión, el efecto significativo de la condición de víctima se hace evidente en ambos estimadores (tanto las víctimas del franquismo como las víctimas del bando nacional durante la guerra civil). Resulta interesante el hecho de que la interacción entre la referencia a la victimización y la edad del encuestado no sea significativa, lo que comporta que el efecto es igual de importante entre los encuestados de todas las edades. El modelo final (Modelo 5) confirma, una vez más, la especificidad de Cataluña y el País Vasco, al tiempo que vuelve a poner de manifiesto que el efecto regional es más fuerte en el caso de los vascos que en el de los catalanes.

Los patrones que emergen de este conjunto de resultados empíricos pueden resumirse del modo siguiente: las medidas de JT que pudieran ser percibidas como más arriesgadas (es decir, la creación de comisiones de la verdad o la celebración de juicios) cuentan con menos respaldo entre los ciudadanos. Aquéllos más proclives a defenderlas son individuos más próximos a la izquierda, más jóvenes, no religiosos, pero también aquéllos con un historial familiar cercano al bando republicano o que han sido víctimas del franquismo. Vivir en comunidades como el País Vasco o Cataluña también hace más probable que los individuos estén a favor de estas políticas, y el efecto diferenciador 
es más intenso en la primera comunidad que en la segunda. En contraste con estas medidas de JT, otras que podrían ser percibidas como menos agresivas (las simbólicas) gozan de un apoyo más amplio en la sociedad. A pesar de estas diferencias, a nivel individual, las actitudes hacia las medidas simbólicas parecen explicarse por factores similares: una combinación de variables individuales, familiares y contextuales que trabajan en una misma dirección. Entre todos ellos, los factores como la ideología y la religiosidad del individuo, así como que la familia fuera víctima de la dictadura, son los más relevantes y se mantienen robustos en todos los modelos y especificaciones.

\section{Conclusiones}

Este artículo, cuyo principal propósito es explicar los determinantes de las actitudes populares hacia la JT en la España actual, representa una contribución a la literatura especializada sobre el tema, que apenas ha recurrido a datos de encuesta. Hemos analizado la JT desagregada en varias medidas que pueden complementarse o bien representar alternativas. Hemos podido observar que la variación en el apoyo a las medidas de JT es fruto de una combinación de variables de tipo individual, familiar (socialización) y contextual. En general, las personas más proclives a apoyar este tipo de políticas tienden a ser de izquierdas, se declaran no religiosos, sus familias han solido combatir en el bando republicano y/o han sido víctimas de la represión franquista. La edad es relevante para predecir el apoyo a estas medidas, de modo que los entrevistados de mayor edad tienen una probabilidad más baja de estar de acuerdo con la JT. No obstante, la edad parece tener de un impacto diferenciado según la población de residencia: el efecto negativo de la edad es más acentuado -en sentido negativo- en poblaciones pequeñas. Ello concuerda con la resistencia a apoyar políticas de JT que se ha observado en localidades pequeñas (Aguilar 2008a).

En cuanto al impacto de la socialización familiar, hemos constatado que, setenta años después de la guerra civil y más de treinta tras la dictadura, el hecho de que el encuestado se declare víctima (bien personalmente, bien por la victimización de su familia) es crucial para explicar sus actitudes actuales hacia la JT. Esta conclusión aconseja devolver la atención necesaria a las experiencias familiares en la formación de las opiniones y actitudes políticas, especialmente si aquéllas fueron traumáticas. Sorprendentemente, el impacto de la victimización no está relacionado con la edad del encuestado (en términos técnicos, la interacción entre la victimización y la edad no es significativa), lo que confirma la decisiva importancia de la transmisión intergeneracional de opiniones sobre acontecimientos traumáticos. La única excepción a esta afirmación se encuentra en el efecto significativo de la interacción entre "victimización" y "edad" en la propensión a apoyar la celebración de juicios; una razón para explicar este hecho podría encontrarse en la mayor probabilidad de que se transmitan de una generación a otra los aspectos más reparadores de la justicia, frente a los más punitivos. 
Al analizar los datos sobre la victimización manifestada por los encuestados junto a variables como la ideología y la religiosidad, surge la duda de si podríamos estar ante un problema de "endogeneidad": podría ser que aquéllos que se identifican con la izquierda tuvieran más tendencia a manifestar experiencias pasadas de victimización que aquéllos que se identifican con la derecha. Si analizamos la relación entre victimización y el posicionamiento subjetivo en la escala izquierda-derecha (Gráfico A.5), se puede observar que las dos variables no se correlacionan de forma evidente. Sin embargo, si realizamos un test Kolmogorov-Smirnov en las dos submuestras (victimizados vis-à-vis no victimizados), éstas aparecen como significativamente diferentes en la media ideológica, lo cual indica que el problema de la endogeneidad podría, efectivamente, existir. Incluyendo la variable ideológica en la regresión obtenemos, en todo caso, un cierto alivio desde el punto de vista metodológico.

Adicionalmente, se han identificado algunas diferencias contextuales (regionales) muy significativas en la probabilidad de estar a favor de las medidas de JT en aquellas Comunidades Autónomas del país en las que predominan identidades nacionales fuertes. No obstante, hay que tener en cuenta que las diferencias también podrían tener lugar en unidades administrativas inferiores, como por ejemplo el municipio (Arjona 2009). La influencia de dichas diferencias contextuales estará supeditada a la existencia no sólo de experiencias de victimización, sino también de un nivel mínimo de conciencia colectiva que facilite los mecanismos para su reproducción.

En términos generales, los resultados de este artículo indican que los acontecimientos violentos y la represión dejan secuelas importantes a largo plazo y que éstas pueden tener efectos importantes en el ámbito político. El mero paso del tiempo no garantiza, necesariamente, el olvido. Precisamente la falta de medidas de reparación (o la escasez de las mismas) puede ser una garantía de la pervivencia de las memorias traumáticas. Por lo que muestran nuestros datos, la victimización, que puede ser más o menos específica (es decir, relacionada con el individuo, la familia o la comunidad política), se transmite de una generación a otra y tiene consecuencias políticas ${ }^{29}$. En este artículo, la atención se ha centrado en las actitudes ante las políticas de JT, que, por definición, están conectadas con los acontecimientos violentos del pasado. No obstante, es probable que estos efectos sean más amplios e influyan, por ejemplo, en la identidad política (Balcells 2007) o en las actitudes sobre género (Wood 2008), entre otros.

Finalmente, nuestro trabajo subraya la importancia de los datos a nivel "micro" para el estudio de las medidas JT por su capacidad para revelar patrones empíricos no predichos. Por ejemplo, en términos meramente descriptivos, este análisis ha clarificado las opiniones de los españoles respecto a estos asuntos trascendiendo el intenso debate público sobre el pasado del que España viene siendo testigo en los últimos años. Nuestros datos permiten demostrar que los españoles son bastante favorables a la apli-

\footnotetext{
${ }^{29}$ Carmil y Breznitz (1990) llegaron a conclusiones similares en su investigación sobre los supervivientes del Holocausto y sus descendientes.
} 
cación de políticas de JT, al contrario de lo que algunos partidos y medios de comunicación han venido sosteniendo (sin evidencia empírica alguna). De hecho, nuestros datos indican que el ciudadano medio español habría respaldado la aplicación de algunas medidas de JT más ambiciosas que las contempladas en la conocida como "Ley de Memoria Histórica". De haber dispuesto con anterioridad de estos datos la polémica suscitada a este respecto habría sido, con toda probabilidad, mucho menor 0 , al menos, menos virulenta. Si bien, como hemos visto, todavía hay un sector de españoles que dice tener miedo a remover el pasado, son claramente mayoritarios los ciudadanos que se atreven a mirarlo sin temor y que opinan que el Estado debe compensar a las víctimas de la guerra y del franquismo, lo que implícitamente supone reconocer los límites de lo que se hizo en la transición. No obstante, ésta continúa siendo muy positivamente valorada y seguramente son mayoría los que piensan que, en aquellas circunstancias, no se podía ir más allá. También parece evidente que esta evolución en la opinión de los españoles respecto a la necesidad de aplicar medidas de JT se ha podido ver beneficiada por la existencia de un contexto internacional que es cada vez más hostil a la impunidad y por el hecho de que, hoy en día, se dispone de una serie de instrumentos jurídicos y políticos para presionar a favor de la reparación de las víctimas, y para evitar que éstas caigan en el olvido, de los que se carecía en el momento en que España transitó hacia la democracia.

\section{RefERENCIAS BibliográficAs}

Acock, A. C. y V. L. Bengtson 1980. "Socialization and Attribution: Actual versus Perceived Similarity Among Parents and Youth." Journal of Marriage and the Family 42:501-515.

Aguilar, P. 2008a. Políticas de la memoria y memorias de la política. Madrid: Alianza Editorial.

Aguilar, P. 2008b. "Transitional or Post-Transitional Justice? Recent developments in the Spanish Case." South European Society \& Politics 4:417-433.

Aguilar, P. 2009. "Whatever Happened to Francoist Socialization? Spaniards' Values and Patterns of Cultural Consumption in the Post-Dictatorial Period." Democratization 16: 455-484.

Arjona, A. 2009. "One National War, Multiple Local Orders: An Inquiry into the Unit of Analysis of War and Post-war Interventions." Pp. 123-150 en Law in Peace Negotiations, coordinado por M. Bergsmo y P. Kalmanovitz. Oslo: FICJC Publications 2, Peace Research Institute.

Balcells, L. 2007. "The effects of wars on political identities: ideological change and continuity after the Spanish Civil War (1936-39)." Presentado en el 103 Annual Meeting of the American Political Science Association, Chicago.

Barahona De Brito, A. C. González-Enríquez y P. Aguilar. eds. 2001. The Politics of Memory. Transtional Justice in Democratizing Societies. Oxford: Oxford University Press. 
Backer, D. 2003. "Civil Society and Transitional Justice: Possibilities, Patterns and Prospects." Journal of Human Rights 2:297-313.

Beck, P. A. y M. Kent Jennings 1991. "Family Traditions, Political Periods, and the Development of Partisan Orientations." The Journal of Politics 53:742-763.

Becker, G. 1983. "A Theory of Competition among Pressure Groups for Political Influence." Quarterly Journal of Economics 98:371-400.

Biro, M. et al. 2004. "Attitudes Toward Justice and Social Reconstruction in Bosnia and Herzegovina and Croatia." Pp. 183-205 en Justice and Community in the Aftermath of Mass Atrocity, coordinado por E. Strover y H. M. Weinstein, My Neighbor, My Enemy. Cambridge: Cambridge University Press.

Carmil, D. y S. Breznitz 1990. "Personal Trauma and World View -Are Extremely Stressful Experiences Related to Political Attitudes, Religious Beliefs, and Future Orientation?." Journal of Traumatic Stress 4:393-405.

Chinchón, J. 2007. "El viaje a ninguna parte: memoria, leyes, historia y olvido sobre la guerra civil y el pasado autoritario en España. Un examen desde el derecho internacional." Revista del Instituto Interamericano de Derechos Humanos 45:119-233.

Dalhouse, M. y J. S. Frideres 1996. "Intergenerational congruency: The role of the family in political attitudes of youth." Journal of Family Issues 17:227-248.

De Greiff, P. y R. Duthie. eds. 2009. Transitional Justice and Development. Making Connections. Nueva York: Social Science Research Council and International Center for Transitional Justice.

Elster, J. 1998. "Coming to Terms with the Past. A Framework for the Study of Justice in the Transition to Democracy." Archives Européennes de Sociologie 39:7-48.

Elster, J. 2004. Closing the Books. Transitional Justice in Historical Perspective. Cambridge: Cambridge University Press.

Elster, J. 2006. ed. Retribution and Reparation in the Transition to Democracy. Cambridge: Cambridge University Press.

Espinoza Cuevas, V., M. L. Ortiz Rojas y P. Rojas Baeza. 2003. Comisiones de la verdad. ¿Un camino incierto? Chile: Corporación de Promoción y Defensa de los Derechos del Pueblo, Asociación para la Prevención de la Tortura.

Gibson, J. L. 2002. "Truth, Justice, and Reconciliation: Judging the Fairness of Amnesty in South Africa." American Journal of Political Science 46:540-556.

Gibson, J. L. 2004a. "Does Truth Lead to Reconciliation? Testing the Causal Assumptions of the South African Truth and Reconciliation Process." American Journal of Political Science 48:201-217.

Gibson, J. L. 2004b. Overcoming Apartheid: Can Truth Reconcile a Divided Nation? Nueva York: Russell Sage Foundation.

Gibson, J. L. 2007. "«Truth» and «Reconciliation» as Social Indicators." Social Indicators Research 81:257-281. 
Gil, A. 2009. La justicia de transición en España. De la amnistía a la memoria histórica. Barcelona: Atelier.

Grodsky, B. 2008. "Weighing the Costs of Accountability: The Role of Institutional Incentives in Pursuing Transitional Justice." Journal of Human Rights 7:353-375.

ICTJ (International Centre for Transitional Justice). 2004. Iraqi Voices: Attitudes Toward Transitional Justice and Social Reconstruction. Disponible en: http: //www.ictj.org

ICTJ (International Centre for Transitional Justice). 2008. Living With Fear: A Population-based Survey on Attitudes about Peace, Justice and Social Reconstruction in Eastern Democratic Republic of Congo. http: //www.ictj.org

Jennings, M. K. y R. G. Niemi 1974. The Political Character of Adolescence. Princeton: Princeton University Press.

Jennings, M. K. y R. G. Niemi 1981. Generations and Politics. Princeton, NJ: Princeton University Press.

Kritz, N. J. ed. 1995. Transitional Justice: How Emerging Democracies Reckon with Former Regimes. Washington: United States Institute of Peace Press.

Koonings, K. y D. Kruijt. eds. 1999. Societies of Fear: The Legacy of Civil War, Violence and Terror in Latin America. Londres: Zed Books.

Longman, T. et al. 2004. "Connecting Justice to Human Experience: attitudes toward accountability and reconciliation in Rwanda." Pp. 206-225 en My Neighbor, My Enemy. Justice and Community in the Aftermath of Mass Atrocity, coordinado por E. Strover y H. M. Weinstein. Cambridge: Cambridge University Press.

Maravall, J. M. 1978. Dictatorship and Political Dissent. Workers and Students in Franco's Spain. Londres: Tavistock.

Martín, I. 2004. Significados y orígenes del interés por la política en dos nuevas democracias: España y Grecia. Madrid: Centro de Estudios Avanzados en Ciencias Sociales del Instituto Juan March.

McAdams, A. J. ed. 1997. Transitional justice and the rule of law in new democracias. Notre Dame, Indiana: University of Notre Dame Press.

Merwe, H. V. D. V. Baxter, V. y A. R. Chapman. eds. 2009. Assesing the Impact of Transitional Justice. Challenges for Empirical Research. Washington: United States Institute of Peace Press.

Miller, R. B. y J. Glass 1989. "Parent-child attitude similarity across the life course." Journal of Marriage and the Family 51:991-997.

Montero, J. R., K. Calvo y A. Martínez 2008. "El voto religioso en España y Portugal." Revista Internacional de Sociología 51:19-54.

Nalepa, M. 2007. "Procedural Fairness and Demand for Transitional Justice: Evidence from East Central Europe." Presentado en el Annual Meeting of the Midwest Political Science Association, Chicago. 
Nalepa, M. 2008. "To Punish the Guilty and Protect the Innocent. Comparing Truth Revelation Procedures." Journal of Theoretical Politics 2:221-245.

Nalepa, M. 2010. Skeletons in the Closet: Transitional Justice in Post-Communist Europe. Cambridge: Cambridge University Press.

Payne, L. A., T. D. Olsen y A. G. Reiter 2008. "Does Transitional Justice Work?" Paper prepared for presentation at the 49th International Studies Association Convention, 26-29 de marzo. San Francisco.

Skaar, E. 1999. "Truth Commissions, Trials or Nothing," Third World Quarterly 20: 1109-1128.

Strover, E. \& H. M. Weinstein. eds. 2004. My Neighbor, My Enemy. Justice and Community in the Aftermath of Mass Atrocity. Cambridge: Cambridge University Press.

Styskal, R. A. y H. J. Sullivan 1975. "Intergenerational Continuity and Congruence on Political Values." Political Research Quarterly 28:516-527.

Tedin, K. L. 1974. "The Influence of Parents on the Political Attitudes of Adolescents." American Political Science Review 68:1579-92.

Teitel, R. 2000. Transitional Justice. Nueva York: Oxford University Press.

Theidon, K. 2006. "The Micropolitics of Reconciliation in Postwar Peru." Journal of Conflict Resolution 50:433-457.

Thoms, O. Ron, J. \& Paris, R. 2008. "The Effects of Transitional Justice Mechanisms." CIPS Working Paper, University of Ottawa, Ottawa.

Wittenberg, J. 2009. Crucibles of Political Loyalty: Church Institutions and Electoral Continuity in Hungary. Nueva York: Cambridge University Press.

Wood, E. 2008. "The Social Processes of Civil War: The Wartime Transformation of Social Networks." Annual Review of Political Science 11:539-61. 
PALOMA AGUILAR es doctora en Ciencias Políticas y Sociología por la UNED y doctora miembro del Instituto Juan March. Es profesora titular del Departamento de Ciencia Política y de la Administración de la UNED y, en la actualidad, directora del Departamento de Publicaciones y Fomento de la Investigación del Centro de Investigaciones Sociológicas. Ha sido Tinker Professor en la Universidad de Madison (Wisconsin).

LAIA BALCELLS es doctora en Ciencias Políticas por la Universidad de Yale, doctora miembro del Instituto Juan March y licenciada en Ciencias Políticas por la Universitat Pompeu Fabra (con Premio Extraordinario). Actualmente es investigadora en el Institut d'Anàlisi Econòmica, CSIC. Es profesora asociada en los departamentos de Ciencias Políticas y Economía de la Universitat Pompeu Fabra de Barcelona.

HÉCTOR CEBOLLA BOADO es doctor en Sociología por la Universidad de Oxford (Nufffield College), doctor miembro del Instituto Juan March y licenciado en Ciencias Políticas por la Universidad Complutense de Madrid. Actualmente es contratado doctor en el Departamento de Estructura Social (Sociología II) de la UNED. Ha sido profesor visitante en la Universidad Autónoma de Madrid y Pompeu Fabra de Barcelona.

RECIBIDO: $30 / 06 / 2009$

ACEPTADO: 09/09/2009

Publicado on-line: 16/12/10 


\section{APÉNDICE DE TABLAS Y GRÁFICOS}

Tabla A.0

Estadísticos descriptivos de las variables.

\begin{tabular}{l|ccccc}
\hline Nombre de la variable & N & Media & Desv. típica & Mín. & Máx. \\
\hline Juicios & 2.525 & 2,36 & 0,87 & 1 & 3 \\
Símbolos & 2.667 & 2,49 & 0,81 & 1 & 3 \\
Monumentos & 2.617 & 2,50 & 0,80 & 1 & 3 \\
Comisiones & 2.426 & 0,52 & 0,49 & 0 & 1 \\
Edad & 2.936 & 47,17 & 18,15 & 18 & 99 \\
Tamaño del municipio & 2.936 & 3,87 & 1,65 & 1 & 7 \\
Interés por la política & 2.919 & 2,08 & 0,88 & 1 & 4 \\
Educación & 2.929 & 1,91 & 0,70 & 1 & 3 \\
Religiosidad & 2.868 & 2,50 & 1,35 & 1 & 6 \\
Ideología & 2.435 & 4,39 & 1,74 & 1 & 10 \\
Víctima del franquismo & 2.936 & 0,24 & 0,42 & 0 & 1 \\
Víctima de los franquistas en la GC & 2.936 & 0,31 & 0,46 & 0 & 1 \\
Familia en el bando franquista en la GC & 2.936 & 0,15 & 0,36 & 0 & 1 \\
Familia en el bando republicano en la GC & 2.936 & 0,32 & 0,46 & 0 & 1 \\
Familia hablaba de política & 2.854 & 1,91 & 0,82 & 1 & 4 \\
Ideología del padre & 2.103 & 4,82 & 2,21 & 1 & 10 \\
Cataluña & 2.936 & 0,23 & 0,42 & 0 & 1 \\
País Vasco & 2.936 & 0,23 & 0,42 & 0 & 1 \\
\hline
\end{tabular}


Tabla A.1.

Regresión logística: creación de una comisión de la verdad para investigar violaciones de derechos bajo el franquismo

\begin{tabular}{|c|c|c|c|c|c|c|c|}
\hline Comisiones & & MO & M1 & M2 & M3 & M4 & M5 \\
\hline Efecto de edad & $\begin{array}{l}\text { Edad } \\
\text { Tamaño del municipio } \\
\text { Tamaño del municipio *edad }\end{array}$ & $\begin{array}{c}-0,023^{* * *} \\
(0,01) \\
-0,144^{*} \\
(0,08) \\
d \quad 0,003^{*} \\
(0,00)\end{array}$ & $\begin{array}{l}-0,008^{* *} \\
(0,00) \\
-0,022 \\
(0,03)\end{array}$ & $\begin{array}{l}-0,006 \\
(0,00) \\
-0,025 \\
(0,03)\end{array}$ & $\begin{array}{l}-0,010^{* * *} \\
(0,00) \\
-0,027 \\
(0,03)\end{array}$ & $\begin{array}{l}-0,011^{* * *} \\
(0,00) \\
-0,027 \\
(0,03)\end{array}$ & $\begin{array}{l}-0,011^{* * *} \\
(0,00) \\
-0,024 \\
(0,03)\end{array}$ \\
\hline Nivel individual & $\begin{array}{l}\text { Interés por la política } \\
\text { Educación } \\
\text { Religiosidad } \\
\text { Ideología }\end{array}$ & & $\begin{array}{l}0,013 \\
(0,06) \\
-0,110 \\
(0,09) \\
-0,175^{* * *} \\
(0,04) \\
-0,340^{* * *} \\
(0,03)\end{array}$ & $\begin{array}{l}-0,027 \\
(0,06) \\
-0,112 \\
(0,09) \\
-0,151^{* * *} \\
(0,05) \\
-0,287^{* * *} \\
(0,04)\end{array}$ & $\begin{array}{l}-0,053 \\
(0,07) \\
-0,127 \\
(0,09) \\
-0,130^{* * \star} \\
(0,05) \\
-0,288^{* * *} \\
(0,04)\end{array}$ & $\begin{array}{l}-0,052 \\
(0,07) \\
-0,126 \\
(0,09) \\
-0,129^{\star * *} \\
(0,05) \\
-0,288^{* * *} \\
(0,04)\end{array}$ & $\begin{array}{l}-0,052 \\
(0,07) \\
-0,132 \\
(0,09) \\
-0,133^{* * *} \\
(0,05) \\
-0,286^{* * *} \\
(0,04)\end{array}$ \\
\hline \multirow{5}{*}{$\begin{array}{l}\text { Socialización } \\
\text { (la referencia } \\
\text { es "en los dos } \\
\text { bandos) }\end{array}$} & $\begin{array}{l}\text { Familia en el bando } \\
\text { franquista en la GC }\end{array}$ & & & $\begin{array}{l}-0,382^{\star *} \\
(0,15)\end{array}$ & $\begin{array}{l}-0,268^{*} \\
(0,16)\end{array}$ & $\begin{array}{l}-0,266^{*} \\
(0,16)\end{array}$ & $\begin{array}{l}-0,264^{*} \\
(0,16)\end{array}$ \\
\hline & $\begin{array}{l}\text { Familia en el bando } \\
\text { republicano en la GC }\end{array}$ & & & $\begin{array}{l}0,075 \\
(0,13)\end{array}$ & $\begin{array}{l}0,005 \\
(0,13)\end{array}$ & $\begin{array}{l}0,003 \\
(0,13)\end{array}$ & $\begin{array}{l}-0,001 \\
(0,13)\end{array}$ \\
\hline & $\begin{array}{l}\text { Familia hablaba de política } \\
\text { Ideología del padre } \\
\text { Victimización durante } \\
\text { el franquismo }\end{array}$ & & & $\begin{array}{l}0,201^{* * *} \\
(0,07) \\
-0,026 \\
(0,03)\end{array}$ & $\begin{array}{l}0,140^{* * *} \\
(0,07) \\
-0,029 \\
(0,03) \\
0,839^{* * *} \\
(0,13)\end{array}$ & $\begin{array}{l}0,139^{\star *} \\
(0,07) \\
-0,029 \\
(0,03) \\
0,700^{*} \\
(0,36)\end{array}$ & $\begin{array}{l}0,137^{*} \\
(0,07) \\
-0,029 \\
(0,03) \\
0,831^{* * *} \\
(0,13)\end{array}$ \\
\hline & $\begin{array}{l}\text { Victimización por los } \\
\text { franquistas durante la GC }\end{array}$ & & & & $\begin{array}{l}0,029 \\
(0,13)\end{array}$ & $\begin{array}{l}0,030 \\
(0,13)\end{array}$ & $\begin{array}{c}0,034 \\
(0,13)\end{array}$ \\
\hline & Edad*victimización & & & & & $\begin{array}{c}0,003 \\
(0,01)\end{array}$ & \\
\hline \multirow{2}{*}{$\begin{array}{l}\text { Diferencias } \\
\text { regionales } \\
\text { (la referencia es } \\
\text { "otras regiones") }\end{array}$} & Cataluña & & & & & & $\begin{array}{l}-0,017 \\
(0,14)\end{array}$ \\
\hline & País Vasco & & & & & & $\begin{array}{l}0,451^{*} \\
(0,27)\end{array}$ \\
\hline Constante & & $\begin{array}{l}1,200 \\
(0,35)\end{array}$ & $\begin{array}{r}2,679 \\
(0,34)\end{array}$ & $\begin{array}{l}2,160 \\
(0,37)\end{array}$ & $\begin{array}{r}2,331 \\
(0,38)\end{array}$ & $\begin{array}{l}2,360^{\star \star *} \\
(0,39)\end{array}$ & $\begin{array}{l}2,326^{* * *} \\
(0,38)\end{array}$ \\
\hline $\begin{array}{l}\mathrm{N} \\
\text { Chi2 }\end{array}$ & & $\begin{array}{l}.7041 .7 \\
20,33^{* * *}\end{array}$ & $\begin{array}{l}7041 . \\
208,84^{\star * *}\end{array}$ & $\begin{array}{l}704 \quad 1 \\
229,89^{* * *}\end{array}$ & $\begin{array}{l}.704 \quad 1 \\
275,177^{\star \star \star}\end{array}$ & $\begin{array}{l}1.704 \quad 1 \\
275,349^{* * *}\end{array}$ & $\begin{array}{l}1.704 \\
278,20^{* * \star}\end{array}$ \\
\hline Aic & & 2346,1172 & 163,6022 & 150,5612 & 2109,274 & 2111,102 & 2110,250 \\
\hline
\end{tabular}

Leyenda: ${ }^{*} p<0,1 ;{ }^{* *} p<0,05 ;{ }^{* *} p<0,01$. 
Tabla A.2

Regresión logística ordinal: celebración de juicios contra los responsables de violaciones de derechos bajo el franquismo

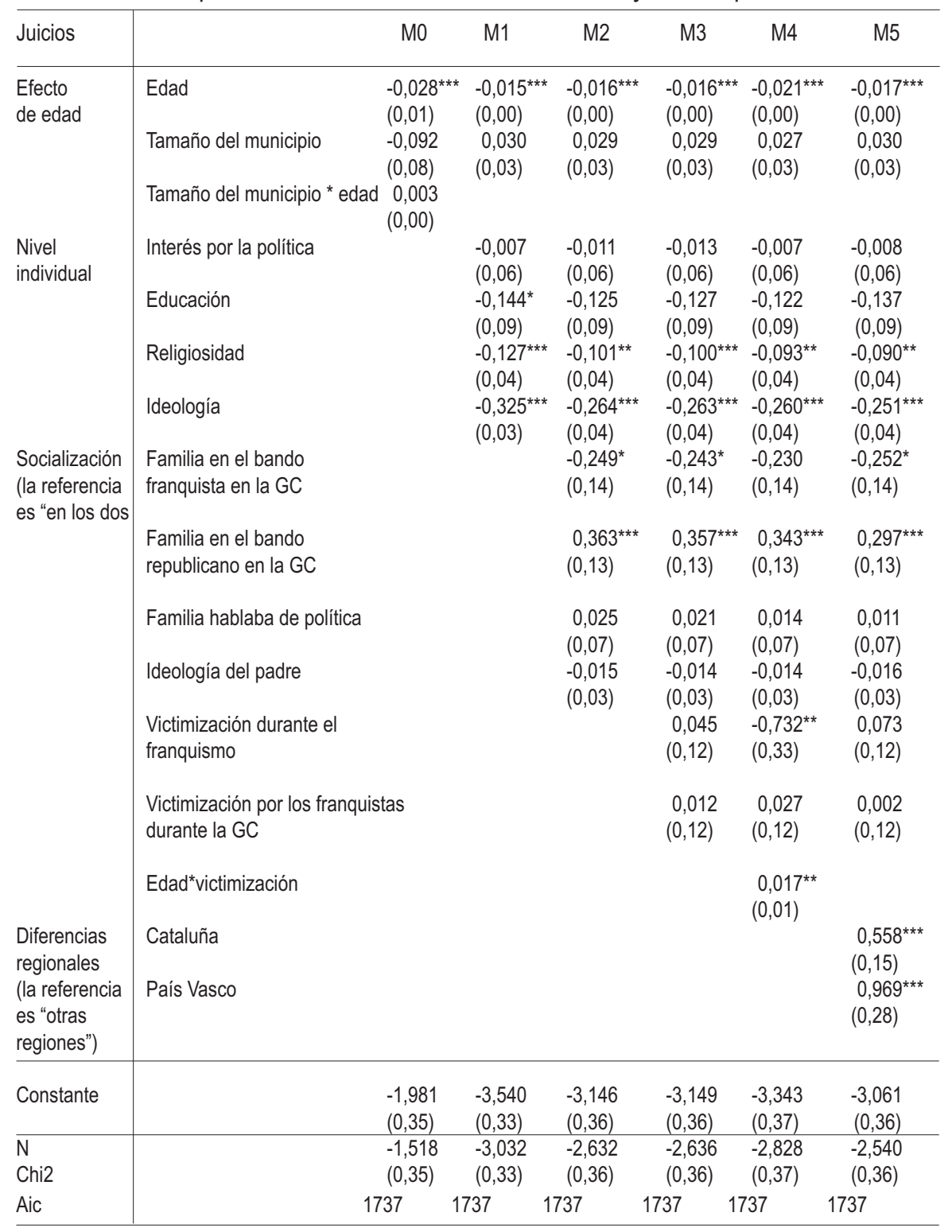

Leyenda: ${ }^{*} p<0,1 ;{ }^{* *} p<0,05 ;{ }^{* * *} p<0,01$. 
Tabla A.3

Regresión logística ordinal: retirada de símbolos que rinden homenaje a Franco y al franquismo

\begin{tabular}{|c|c|c|c|c|c|c|c|}
\hline Símbolos & & MO & M1 & M2 & M3 & M4 & M5 \\
\hline Efecto de edad & $\begin{array}{l}\text { Edad } \\
\text { Tamaño del municipio } \\
\text { Tamaño del municipio *edad }\end{array}$ & $\begin{array}{l}-0,032^{\star \star *} \\
(0,01) \\
-0,284^{\star \star *} \\
(0,08) \\
0,006^{\star \star *} \\
(0,00)\end{array}$ & $\begin{array}{l}0,001 \\
(0,00) \\
-0,023 \\
(0,03)\end{array}$ & $\begin{array}{l}0,001 \\
(0,00) \\
-0,023 \\
(0,03)\end{array}$ & $\begin{array}{l}-0,001 \\
(0,00) \\
-0,025 \\
(0,03)\end{array}$ & $\begin{array}{l}-0,003 \\
(0,00) \\
-0,026 \\
(0,03)\end{array}$ & $\begin{array}{l}-0,003 \\
(0,00) \\
-0,024 \\
(0,03)\end{array}$ \\
\hline Nivel individual & $\begin{array}{l}\text { Interés por la política } \\
\text { Educación } \\
\text { Religiosidad } \\
\text { Ideología }\end{array}$ & & 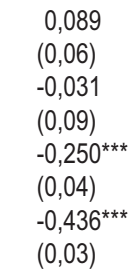 & $\begin{array}{l}0,103 \\
(0,07) \\
-0,014 \\
(0,09) \\
-0,220^{* \star *} \\
(0,04) \\
-0,387^{* \star *} \\
(0,04)\end{array}$ & $\begin{array}{l}0,089 \\
(0,07) \\
-0,032 \\
(0,09) \\
-0,209^{\star \star \star} \\
(0,04) \\
-0,383^{* \star \star} \\
(0,04)\end{array}$ & $\begin{array}{l}0,091 \\
(0,07) \\
-0,031 \\
(0,09) \\
-0,208^{* \star *} \\
(0,04) \\
-0,382^{* \star *} \\
(0,04)\end{array}$ & $\begin{array}{l}0,093 \\
(0,07) \\
-0,044 \\
(0,09) \\
-0,203^{\text {** }} \\
(0,04) \\
-0,374^{\text {** }} \\
(0,04)\end{array}$ \\
\hline $\begin{array}{l}\text { Socialización } \\
\text { (la referencia es } \\
\text { en los dos } \\
\text { bandos }\end{array}$ & $\begin{array}{l}\text { Familia en el bando } \\
\text { franquista en la GC } \\
\text { Familia en el bando } \\
\text { republicano en la GC } \\
\text { Familia hablaba de política } \\
\text { Ideología del padre } \\
\text { Victimización durante } \\
\text { el franquismo } \\
\text { Victimización por los } \\
\text { franquistas durante la GC } \\
\text { Edadvictimización }\end{array}$ & & & $\begin{array}{l}-0,449^{\star \star *} \\
(0,14) \\
0,271^{\star *} \\
(0,14) \\
\\
-0,007 \\
(0,07) \\
0,016 \\
(0,03)\end{array}$ & $\begin{array}{c}-0,384^{* * *} \\
(0,14) \\
0,183 \\
(0,14) \\
\\
-0,042 \\
(0,07) \\
0,019 \\
(0,03) \\
0,366^{* * *} \\
(0,13) \\
\\
0,248^{*} \\
(0,13)\end{array}$ & $\begin{array}{c}-0,377^{\star *} \\
(0,14) \\
0,178 \\
(0,14) \\
\\
-0,044 \\
(0,07) \\
0,020 \\
(0,03) \\
0,107 \\
(0,36) \\
\\
0,253^{\star} \\
(0,13) \\
\\
0,006 \\
(0,01)\end{array}$ & $\begin{array}{l}-0,386^{\star \star \star} \\
(0,15) \\
0,121 \\
(0,14) \\
\\
-0,050 \\
(0,07) \\
0,020 \\
(0,03) \\
0,384^{\star \star *} \\
(0,14) \\
\\
0,234^{*} \\
(0,13)\end{array}$ \\
\hline $\begin{array}{l}\text { Diferencias } \\
\text { regionales } \\
\text { (la referencia es } \\
\text { "otras regiones") }\end{array}$ & $\begin{array}{l}\text { Cataluña } \\
\text { País Vasco }\end{array}$ & & & & & & $\begin{array}{l}0,456^{\star * \star} \\
(0,16) \\
1,464^{\star \star *} \\
(0,36)\end{array}$ \\
\hline Constante & & $\begin{array}{l}-2,666^{* \star *} \\
(0,35)\end{array}$ & $\begin{array}{l}-3,803^{* * *} \\
(0,35)\end{array}$ & $\begin{array}{l}-3,365^{* * *} \\
(0,38)\end{array}$ & $\begin{array}{l}-3,410^{* * *} \\
(0,38)\end{array}$ & $\begin{array}{l}-3,463^{* * *} \\
(0,38)\end{array}$ & $\begin{array}{l}-3,347^{\star \star *} \\
(0,38)\end{array}$ \\
\hline $\begin{array}{l}\mathrm{N} \\
\text { Chi2 }\end{array}$ & & $\begin{array}{l}-2,171^{\star \star \star} \\
(0,35)\end{array}$ & $\begin{array}{l}-3,217^{* * *} \\
(0,34)\end{array}$ & $\begin{array}{l}-2,773^{* * *} \\
(0,37)\end{array}$ & $\begin{array}{l}-2,815^{\star \star *} \\
(0,37)\end{array}$ & $\begin{array}{l}-2,867^{\star \star *} \\
(0,38)\end{array}$ & $\begin{array}{l}-2,743^{\star \star *} \\
(0,38)\end{array}$ \\
\hline Aic & \multicolumn{2}{|c|}{1.807} & 1.807 & .807 & 1.807 & 1.807 & 807 \\
\hline
\end{tabular}

Leyenda: ${ }^{*} p<0,1 ;{ }^{* *} p<0,05 ;{ }^{* * *} p<0,01$ 
Gráficos A.1.

Sentimientos hacia la guerra civil y el franquismo
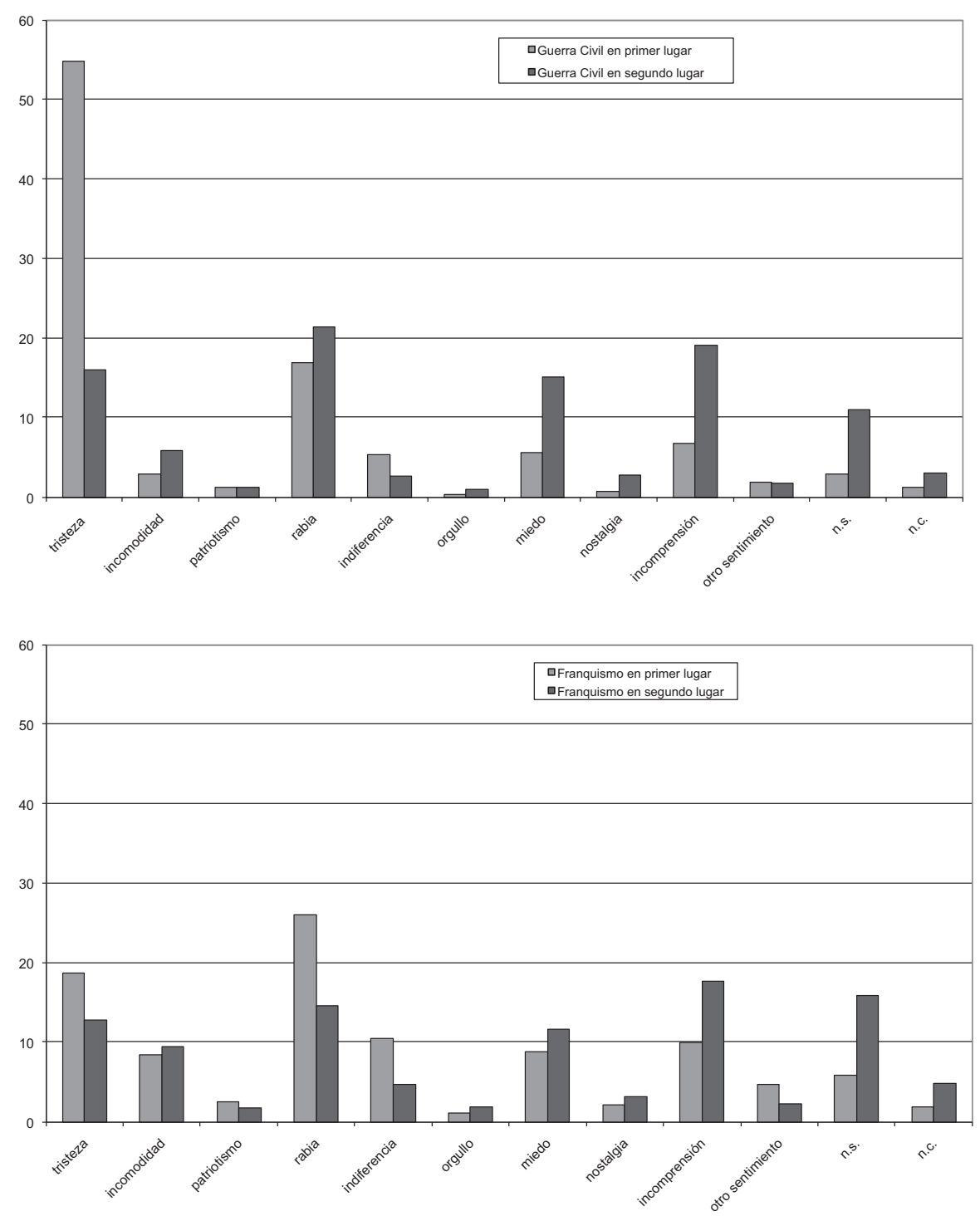

Fuente: CIS 2760. 


\section{Gráfico A.2}

Respuestas sobre recuerdo familiar de participación en la guerra civil por año de recogida

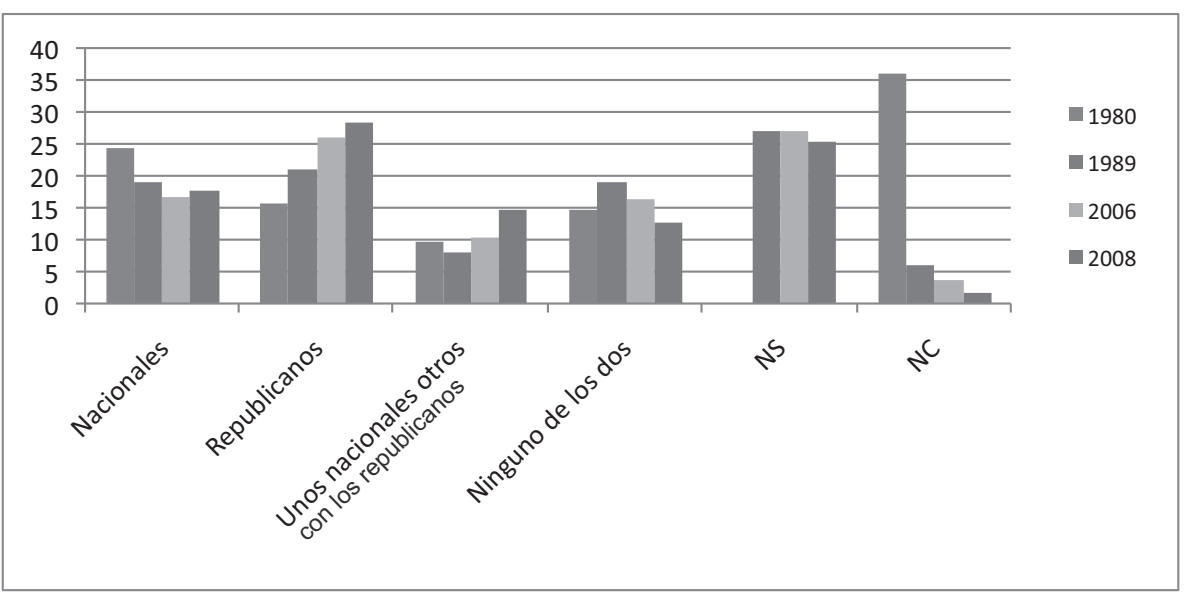

Fuente: CIS 2760 (2008), CIS 2631 (2006), CIS 1788 (1989), CIS 1237 (1980)

\section{Gráfico A.3}

Porcentaje de NS/NC por cohorte ante la pregunta sobre la existencia de hasta tres víctimas en la familia del encuestado

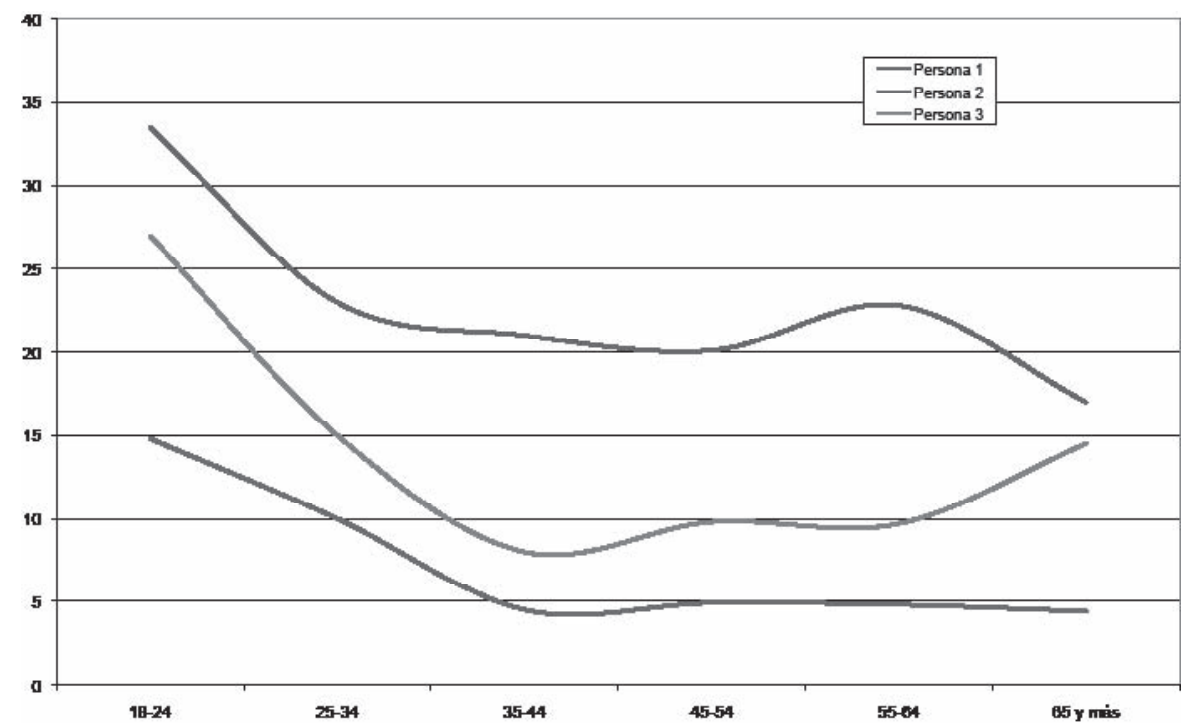

Fuente: CIS 2760 . 
Gráficos A.4.

Las variables dependientes.

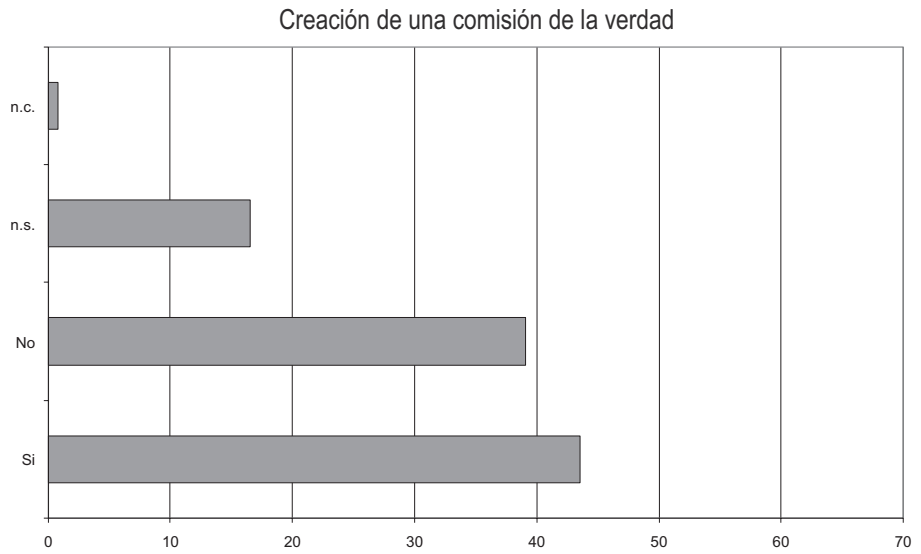

Celebración de juicios

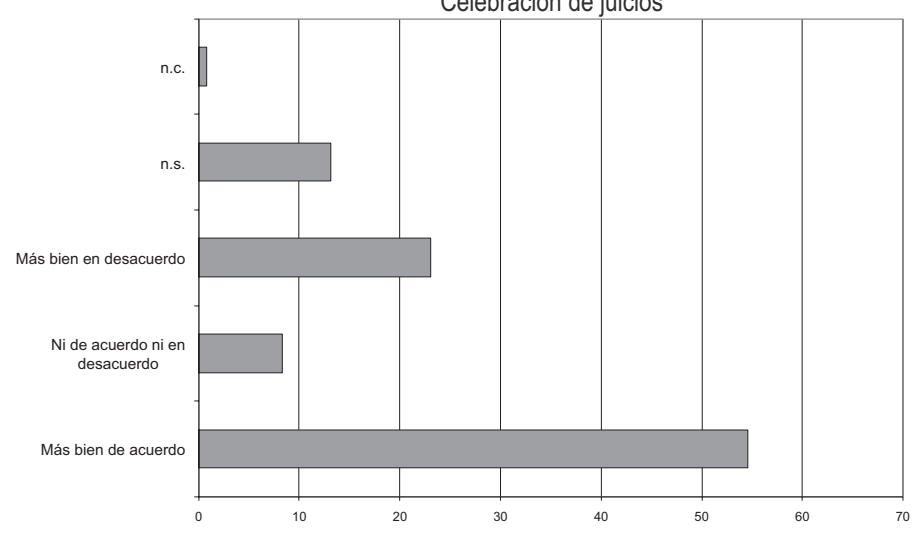

Retirada de símbolos

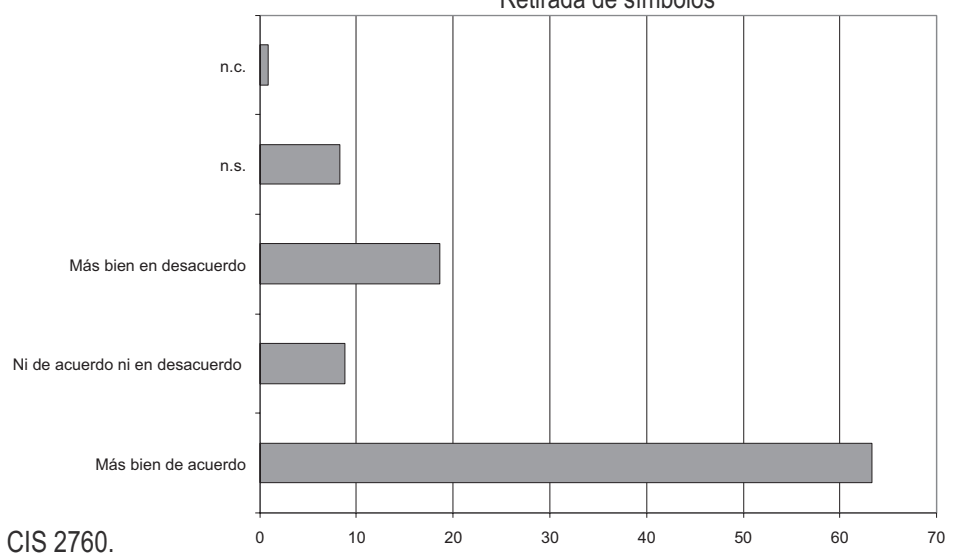

Fuente: CIS 2760.

RIS, VOL.69. No 1, ENERO-ABRIL, 59-90, 2011. ISSN: 0034-9712. DOI: 10.3989/ris.2009.06.30 
Gráfico A.5

Distribución en la escala izquierda-derecha por victimización del encuestado o su entorno

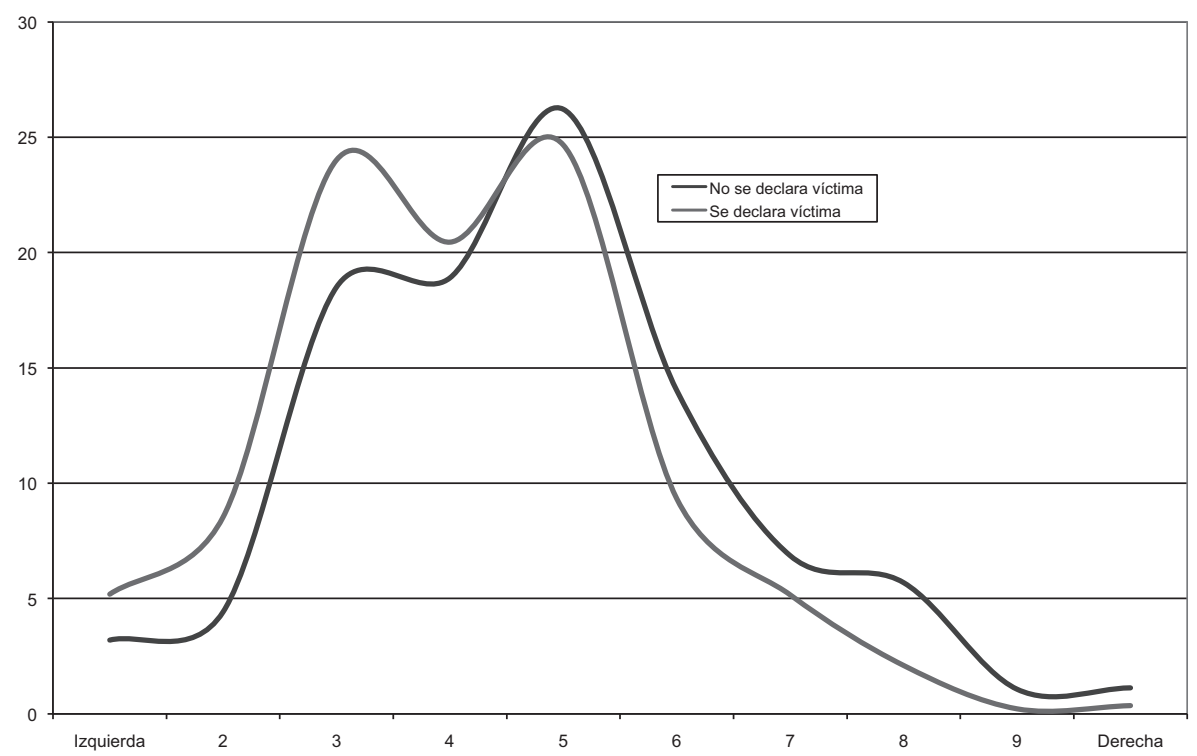

Fuente: CIS 2760. 